\title{
An Unusual Cause of Dysphagia in a Young Patient: Mediastinal Bronchogenic Cyst
}

\author{
Simant Singh Thapa ${ }^{\mathrm{a}, \mathrm{c}}$, Jeffrey Scott ${ }^{\mathrm{b}}$
}

\begin{abstract}
Bronchogenic cysts are rare congenital foregut malformations that develop due to abnormal budding of the embryonic foregut and tracheobronchial tree. Patients typically present during the second decade of life with respiratory symptoms. We present a 22-year-old patient who presented with dysphagia as initial symptom which is very uncommon. This makes it interesting and misleading as it can initially pursue evaluation for gastrointestinal pathology and cause further delay in reaching the diagnosis. Bronchogenic cysts appear on chest radiograph as round, water-density masses. CT typically shows sharply marginated cystic mediastinal masses of soft tissue. On histologic examination, the cyst is lined by respiratory epithelium with occasional foci of squamous metaplasia. The presence of cartilage plates is the most reliable diagnostic criterion. The management of a bronchogenic cyst consists of surgical excision by video-assisted thoracoscopy (VATS) or thoracotomy.
\end{abstract}

Keywords: Bronchogenic cyst; Dysphagia; Misleading presentation

\section{Introduction}

Bronchogenic cysts are rare congenital foregut malformations that develop due to abnormal budding of the embryonic foregut and tracheobronchial tree $[1,2]$. Here we present a case of mediastinal bronchogenic cyst presenting as worsening dysphagia in a young male, which is very uncommon and misleading presentation.

\section{Case Report}

A 22-year-old male presented with 2-month history of diffi-

\section{Manuscript submitted April 3, 2018, accepted April 9, 2018}

aDepartment of Internal Medicine, Saint Vincent Hospital, Worcester, MA 01608, USA

bepartment of Pulmonary and Critical Care, Saint Vincent Hospital, Worcester, MA 01608, USA

${ }^{\mathrm{c} C}$ Corresponding Author: Simant Singh Thapa, Department of Internal Medicine, Saint Vincent Hospital, Worcester, MA 01608, USA.

Email: thapasimant@gmail.com

doi: https://doi.org/10.14740/jmc3053w culty swallowing solid food. He felt as food being stuck in the mid-chest region. He could drink liquids without any problem. He denied any history of shortness of breath, nausea, vomiting, abdominal pain or reflux symptoms. He also complained of a runny nose and productive cough of 5 days duration. He denied alcohol intake, smoking or recreational drug abuse. There was no family history of cancer. On examination, his vital signs showed the temperature of $37.2^{\circ} \mathrm{C}$, pulse $88 / \mathrm{min}$, blood pressure 110/60 $\mathrm{mm} \mathrm{Hg}$, respiration rate $16 / \mathrm{min}$ and $\mathrm{SpO}_{2}$ of $98 \%$ on room air. His head to toe physical examination was normal. A chest X-ray was obtained for his upper respiratory symptoms which revealed clear lungs field but soft tissue prominence medially in the right hilar region (Fig. 1). CT scan of chest with contrast showed a subcarinal cystic lesion compressing the adjacent portion of the esophagus and left atrium (Fig. 2a, b). After discussing the diagnosis of bronchogenic cyst, the patient was given the option of surgical excision of the cyst. The patient decided to undergo cyst removal and the cyst was excised surgically through a right thoracotomy. Histology evaluation showed cyst wall lined with respiratory epithelium consistent with a bronchogenic cyst (Fig. 3). No dysplastic or malignant cells were visualized. Following surgery, his dysphagia resolved.

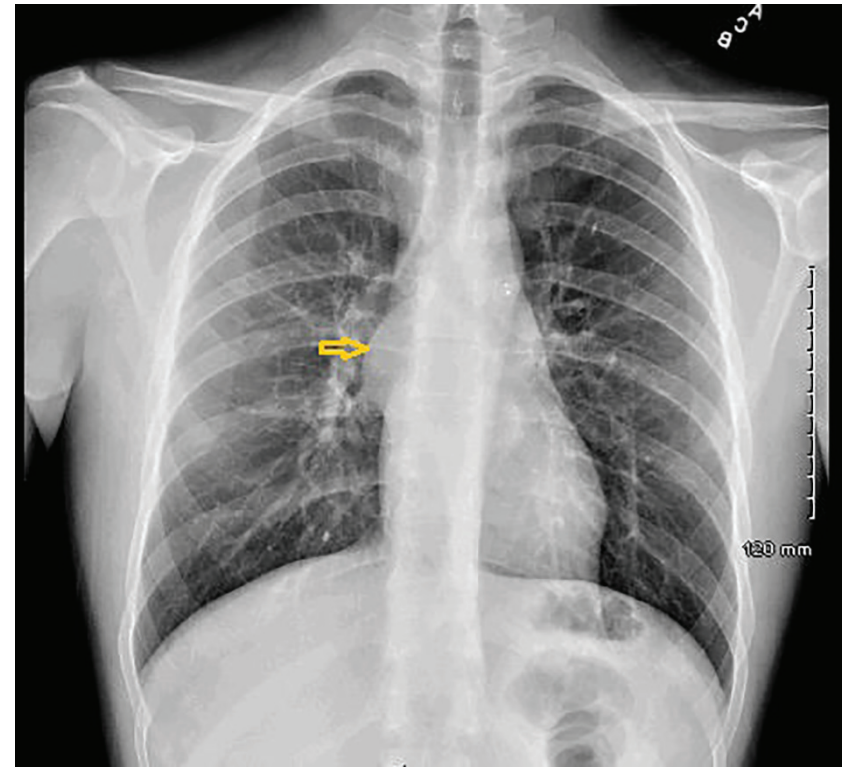

Figure 1. CXR showing smooth subcarinal mass medially in the right hilar region. 

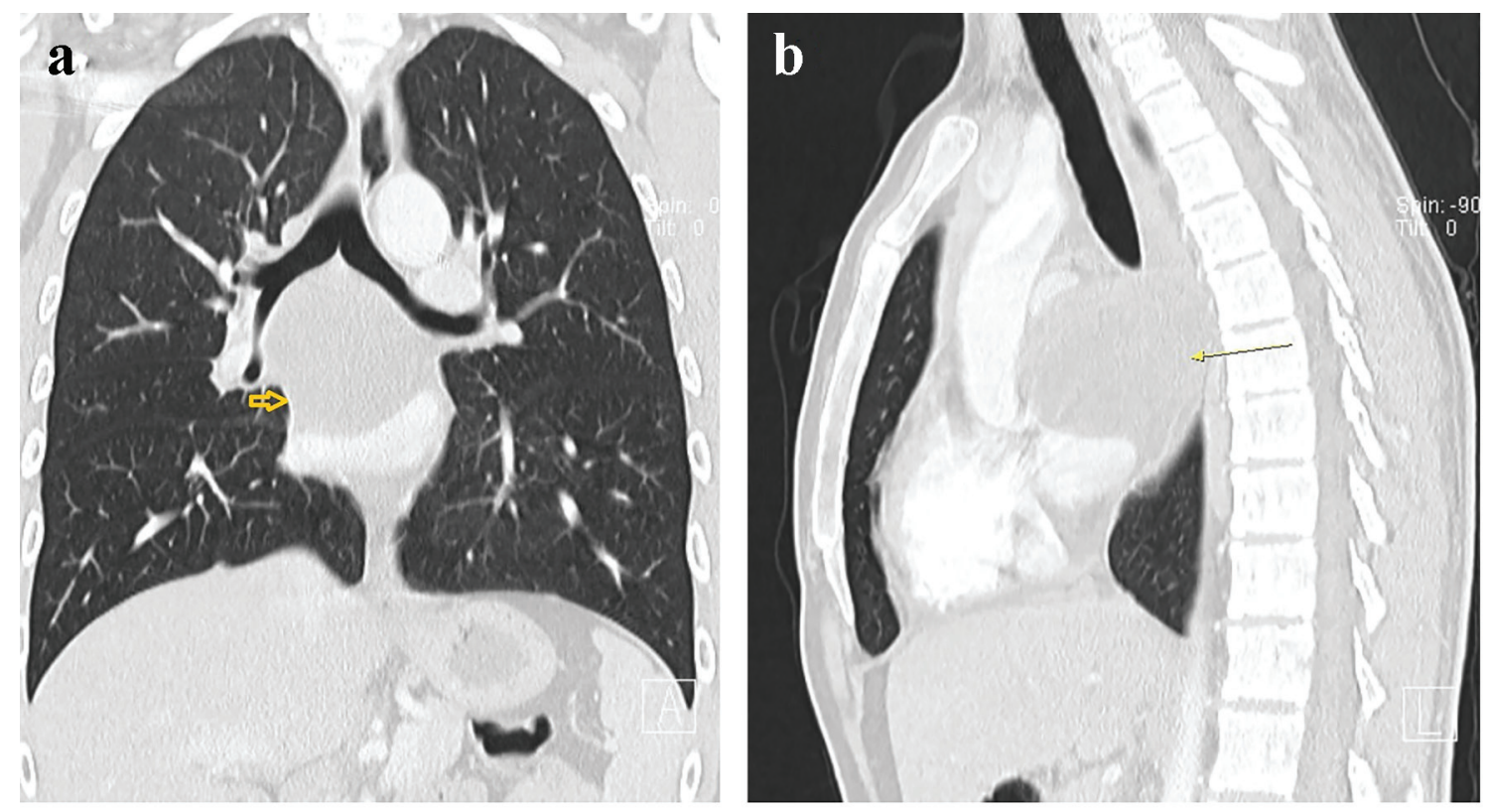

Figure 2. Round subcarinal cystic mass $7.2 \times 6 \mathrm{~cm}$ splaying the carina with mass effect upon the adjacent portion of the esophagus and left atrium: (a) coronal; (b) sagittal.

\section{Discussion}

Bronchogenic cysts account for $6-15 \%$ of primary mediastinal masses and comprise up to $40-50 \%$ of all congenital mediastinal cysts $[1,2]$. Bronchogenic cysts are usually detected incidentally on chest radiographs. Patients typically present during the second decade of life with a recurrent cough, dyspnea or wheeze [3]. Our patient had an unusual initial presentation of dysphagia which is very uncommon and makes it interesting as it can initially pursue evaluation for gastrointestinal pathology and cause further delay in reaching a diagnosis. The similar presentation has been described by Kapoor et al, Manish et al and Chih-Hao Chen et al [4-6]. In all of these cases, gastrointestinal evaluation was initially pursued with barium swallow

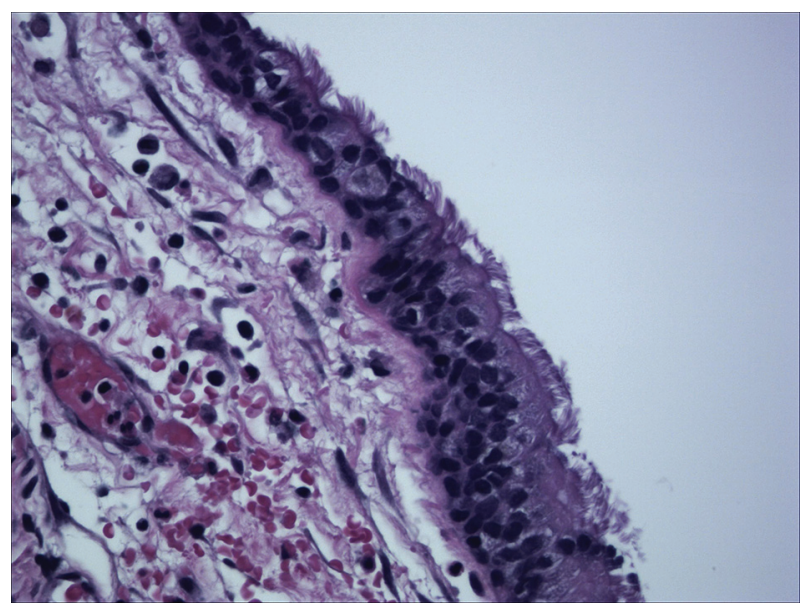

Figure 3. Cyst wall lined with respiratory epithelium consistent with a bronchogenic cyst. and esophagogastroduodenoscopy.

Bronchogenic cysts appear on chest radiograph as round, water-density masses. CT typically shows sharply marginated cystic mass of soft tissue or water attenuation. On histologic examination, the cyst is lined by respiratory epithelium with occasional foci of squamous metaplasia and the wall resembles that of larger airways and contains smooth muscle, glands, and cartilage. The presence of cartilage plates is the most reliable diagnostic criterion [7, 8]. Complications include infection, compression of adjacent structures, intracystic hemorrhage, rupture, bronchial fistula, pneumothorax and rarely malignant transformation $[9,10]$. Even asymptomatic bronchogenic cysts are recommended to be removed surgically unless refused by the patient or a close follow-up is possible. This is to prevent the development of complications later since around 40 and $70 \%$ of cases presents with clinical manifestations in a relatively short time [11-13]. The management of a bronchogenic cyst consists of surgical excision by video-assisted thoracoscopy (VATS) or thoracotomy $[10,13]$.

\section{Conclusion}

Our case report highlights unusual presentation of the bronchogenic cyst as dysphagia which can be misleading and may cause a delay in reaching the diagnosis. It also highlights the importance of considering congenital mediastinal cysts as a differential in young patients with dysphagia.

\section{Consent}

Written informed consent has been obtained from the patient 
before writing the article.

\section{Conflict of Interest}

All the participating authors disclose no conflict of interest.

\section{Funding}

None.

\section{Authorship}

All authors had access to the data and played a role in writing and critical review of this manuscript.

\section{References}

1. Ribet ME, Copin MC, Gosselin B. Bronchogenic cysts of the mediastinum. J Thorac Cardiovasc Surg. 1995;109(5):1003-1010.

2. Berrocal T, Madrid C, Novo S, Gutierrez J, Arjonilla A, Gomez-Leon N. Congenital anomalies of the tracheobronchial tree, lung, and mediastinum: embryology, radiology, and pathology. Radiographics. 2004;24(1):e17.

3. Patel SR, Meeker DP, Biscotti CV, Kirby TJ, Rice TW. Presentation and management of bronchogenic cysts in the adult. Chest. 1994;106(1):79-85.

4. Kapoor S, Abed J, Dalapathi V, Prajapati S, Bhora FY,
Mankal PK, Kotler DP. A bronchogenic cyst presenting as dysphagia. ACG Case Rep J. 2015;2(4):194-195.

5. Tiwari MK, Yadav R, Mathur RM, Shrivastava CP. Mediastinal bronchogenic cyst presenting with dysphagia and back pain. Lung India. 2010;27(2):86-88.

6. Chen CH, Ho C, Yang LY, Huang YZ, Hung TT. Unusual presentation of dysphagia caused by bronchogenic cyst. JRSM Short Rep. 2011;2(9):72.

7. Hernanz-Schulman M. Cysts and cystlike lesions of the lung. Radiol Clin North Am. 1993;31(3):631-649.

8. McAdams HP, Kirejczyk WM, Rosado-de-Christenson ML, Matsumoto S. Bronchogenic cyst: imaging features with clinical and histopathologic correlation. Radiology. 2000;217(2):441-446.

9. Endo C, Imai T, Nakagawa H, Ebina A, Kaimori M. Bronchioloalveolar carcinoma arising in a bronchogenic cyst. Ann Thorac Surg. 2000;69(3):933-935.

10. Mondello B, Lentini S, Familiari D, Barresi P, Monaco F, Sibilio M, La Rocca A, et al. Thoracoscopic resection of a paraaortic bronchogenic cyst. J Cardiothorac Surg. 2010;5:82.

11. Kirmani B, Kirmani B, Sogliani F. Should asymptomatic bronchogenic cysts in adults be treated conservatively or with surgery? Interact Cardiovasc Thorac Surg. 2010;11(5):649-659.

12. Cosio PM, Cosio LL, Lezama A, Rios L. Bronchogenic cyst: Report of a case and review of the literature. Neumol cir Torax. 2014;73(1):24-34.

13. Jimenez Merchan R, Congregado Loscertales M, Gallardo Valera G, Ayarra Jarne J, Loscertales J. [Resection of 8 mediastinal bronchogenic cysts by video-assisted thoracoscopy]. Arch Bronconeumol. 2008;44(4):220-223. 